\title{
Vivências de homens frente ao diagnóstico de câncer de próstata
}

\author{
Experiences of men facing the diagnosis of prostate cancer
}

\author{
Stefanie Miranda Porto ${ }^{a}$, Gabriela Borges Carvalho ${ }^{\mathrm{b}}$, Maira Julyê Mota Fernandes ${ }^{\mathrm{b}}$, \\ Cintia Bragheto Ferreira \\ a Psicóloga graduada pela Universidade Federal de Goiás, Regional Jataí. \\ ${ }^{\text {b }}$ Graduanda do Curso de Psicologia da Universidade Federal de Goiás, Regional Jataí. \\ c Psicóloga. Doutora em Enfermagem em Saúde Pública pela Escola de Enfermagem de Ribeirão Preto da Universidade de São Paulo (USP). \\ Professora Adjunta do Curso de Psicologia da Universidade Federal de Goiás, Regional Jataí.
}

RESUMO

Objetivo: Identificar e descrever as vivências de homens frente ao diagnóstico de câncer de próstata, assim como apresentar as estratégias de enfrentamento destes homens para lidarem com as repercussões do adoecimento.

Materiais e Métodos: Pesquisa qualitativa, com entrevistas semiestruturadas, que envolveu oito homens diagnosticados com câncer de próstata.

Resultados: A análise das entrevistas resultou em três eixos temáticos: a identidade masculina diante do adoecimento por câncer de próstata, o diagnóstico, e o tratamento e suas implicações. Os resultados evidenciaram que o diagnóstico de câncer de próstata despertou sentimentos de angústia e ansiedade nos participantes ao associarem a enfermidade à morte. Além disso, o adoecimento promoveu mudanças significativas na vida dos homens entrevistados, afetando suas identidades. Diante do sofrimento experimentado, buscaram apoio na família, nos médicos e na religiosidade/ espiritualidade.

Conclusão: O sofrimento causado nos participantes a partir do diagnóstico de câncer de próstata, que foi enfrentado com o auxílio da família, dos médicos e da religiosidade/espiritualidade, mostra a importância de redes de suporte para o enfrentamento de problemas como o diagnóstico dessa enfermidade.

Palavras-chave: neoplasias da próstata; diagnóstico; masculinidade.

Objective: To identify and describe the experiences of men facing the diagnosis of prostate cancer, as well as to present the coping strategies of these men to deal with the repercussions of the illness.

Materials and Methods: Qualitative research, with semi-structured interview of eight men who were diagnosed with prostate cancer. Results: The analysis of the interviews resulted in three themes: the "male identity" before the prostate cancer disease, the diagnosis, and the treatment and its implications. The results showed that prostate cancer diagnosis provoked feelings of distress and anxiety to the participants who associate the illness to death. Further, the illness promoted significant changes in the interviewed men's lives, affecting their identities. Facing a suffering experience, they sought for support in the family, physicians and in religion/spirituality. Conclusion: The suffer caused by the diagnosis of prostate cancer, which was managed with the help of family, physicians and religion/ spirituality, shows the importance of support networks for dealing with issues such as the diagnosis of such illness.

Keywords: prostatic neoplasms; diagnosis; masculinity. 


\section{INTRODUÇÃO}

Atualmente o câncer de próstata é considerado um problema de saúde pública em nível global ${ }^{1}$. No Brasil, é o tipo de neoplasia mais prevalente entre os homens, tendo sido estimado 61.200 novos casos para o ano de $2016^{2}$. Dessa forma, o câncer de próstata se tornou uma das formas de câncer mais comuns na população masculina e estima-se que um em cada doze homens seja diagnosticado com a doença ao longo da vida ${ }^{3}$.

Diversos fatores são apontados como determinantes para o desenvolvimento do câncer de próstata; dentre eles destacam-se: a maior expectativa de vida, as constantes campanhas para o diagnóstico da doença, além das influências ambientais e alimentares ${ }^{4,5}$. Entretanto, mesmo com o crescente investimento na implementação de políticas públicas e programas de saúde voltados para a prevenção e diagnóstico precoce, o câncer ainda se apresenta como uma das principais causas de morte em todo o mundo ${ }^{6}$.

Um fator que impede o diagnóstico precoce do câncer de próstata é que os homens se mostram parcialmente distantes dos serviços de saúde. O preconceito, o medo, o machismo, além de pensamentos previamente formados como, por exemplo, a fantasia de perda de virilidade, acabam impedindo a busca pela prevenção da doença, e se necessário, até mesmo seu tratamento eficiente. Além disso, na construção da identidade de ser homem com enfoque nos cuidados à saúde, muitos reprimem suas necessidades e recusam-se a admitir a dor e o sofrimento, negando vulnerabilidades e fraquezas constituintes de todo ser humano ${ }^{7,8}$.

A ausência dos homens nos serviços de saúde ainda se deve ao medo da descoberta de uma doença grave e também à vergonha da exposição do seu corpo perante um profissional de saúde, particularmente a região anal, no caso da prevenção do câncer de próstata ${ }^{3}$. Pela conotação sexual que adquire, a prevenção dessa doença torna-se um assunto relacionado à sexualidade masculina que ameaça a virilidade ${ }^{9}$ e afeta o imaginário do homem, em uma sociedade considerada machista, patriarcal e sexista ${ }^{10,11}$. Esse exame é uma prática que pode suscitar no homem o medo da dor, tanto física quanto simbólica ${ }^{11}$. Quando se trata de um exame dessa natureza, a adoção da conduta preventiva pode ser bloqueada não só pelo preconceito, mas também pelo déficit de educação sanitária da população relacionada à prevenção $0^{12}$.

Na sociedade ocidental, o simbolismo construído sobre o câncer é o de uma doença que invade o corpo, incurável, misteriosa, que gera sofrimento e perdas ${ }^{13}$. Os homens consideram o câncer como uma doença grave, complexa e fortemente associada à morte ${ }^{6,13}$. Mesmo com os progressos dos meios diagnósticos e terapêuticos que tem ampliado a sobrevivência dos pacientes, essas crenças persistem ${ }^{13}$. O diagnóstico é vivenciado como um impacto e um choque, demonstrando o quanto essa experiência é agressiva e mutiladora $^{6}$, provocando reações emocionais como medo, tristeza, ansiedade e depressão $0^{6,14,15}$, além de dependência, interrupção de relações sociais e profissionais ${ }^{7}$ e o defrontarse com fragilidades, limitações e necessidades de cuidados, até então negligenciadas e comumente associadas ao feminino ${ }^{6}$. Contudo, o diagnóstico e as terapêuticas do câncer podem representar uma segunda chance de vida ${ }^{13}$.

Para além das reações emocionais desencadeadas pelo diagnóstico de câncer, compreende-se que essas reações, para serem melhor compreendidas, necessitam ser localizadas historicamente, sobre o que se espera ser homem e ser mulher que, por exemplo, de acordo com a moral que rege o modelo de conjugalidade tradicional ${ }^{16}$, mostra que esses papéis são socialmente cristalizados, interiorizados ${ }^{6,17,18}$, naturalizados ${ }^{6}$ e envolvem prerrogativas tais como, que para ser homem é necessário trabalhar, ser o provedor da família e possuir uma posição de autoridade, e para ser mulher é preciso ser sensível, dona de casa e cuidadora dos filhos ${ }^{2,16,19}$.

Assim, o homem que antes era o provedor, forte e viril, devido ao câncer de próstata, necessita reconstruir sua identidade numa nova perspectiva de ser homem ${ }^{8}$. Dessa forma, o diagnóstico de câncer coloca os homens em uma nova condição que se contrapõe aos modos como cotidianamente exercitam e vivenciam suas masculinidades ${ }^{6,20}$.

A vivência do câncer de próstata implica ainda em algumas dificuldades decorrentes das intervenções terapêuticas, que em geral incluem a prostatectomia radical, a quimioterapia e a radioterapia. Em consequência desses procedimentos, o paciente poderá ter que lidar com sequelas como diminuição da libido, impotência sexual e incontinência urinária. Sendo assim, o câncer de próstata é uma doença que impacta fortemente o cotidiano dos homens afetados ${ }^{1,20}$.

A partir dos estudos apresentados, constata-se que o paciente com câncer de próstata tem sua vida modificada em suas dimensões físicas, psíquicas e socias ${ }^{1}$. Com isso, verifica-se a necessidade de pesquisas que considerem o modo particular que homens vivenciam o diagnóstico do câncer de próstata, com aspectos socioculturais como o de homens residentes em municípios de pequeno porte, distantes dos grandes centros urbanos brasileiros, sendo este o interesse desta investigação. Sendo assim, o presente estudo foi realizado com o objetivo de identificar e descrever as vivências de homens frente ao diagnóstico de câncer de próstata, bem como as estratégias encontradas por estes para lidarem com as repercussões do adoecimento. 


\section{MATERIAIS E MÉTODOS}

O estudo realizado foi do tipo qualitativo. Foram entrevistados pacientes cadastrados em um Núcleo Regional de Combate ao Câncer, localizado em um município do interior de Goiás, caracterizado como uma associação civil, assistencial, de direito privado e não governamental. Atualmente, a instituição conta com aproximadamente 1145 pessoas cadastradas, sendo que, durante 21 anos de registro, encontraram-se 294 homens cadastrados entre a prevenção do câncer de próstata e o diagnóstico positivo.

Dentre todos os homens cadastrados com câncer de próstata, foram selecionados aqueles registrados entre janeiro de 2014 e março de 2015, o que resultou em um total de 20 homens. O período de registro para o levantamento dos dados foi inicialmente definido a partir da perspectiva de que as conversas sobre o diagnóstico do câncer seriam muito mais presentes nas entrevistas quanto mais próximas as mesmas fossem realizadas da data de recebimento da notícia sobre a confirmação da doença. Contudo, no acontecer das entrevistas, verificou-se que dois participantes, mesmo com registros recentes na fonte de dados, haviam recebido o diagnóstico há bastante tempo, mas, mesmo assim esses dois casos foram mantidos, em razão da riqueza de seus depoimentos. Dentre os 20 homens inicialmente selecionados, 6 não tiveram interesse em participar, 2 não residiam mais no município onde os dados foram coletados, 1 veio a óbito, 1 estava hospitalizado e 1 deles a família optou por não revelar o diagnóstico. Sendo assim, foram realizadas ao todo 9 entrevistas. Porém, 8 entrevistas foram utilizadas na pesquisa, visto que em uma delas um familiar participou da entrevista junto do participante e respondeu todas as perguntas em nome do entrevistado.

O estudo foi submetido a um Comitê de Ética em Pesquisa e aprovado (protocolo no 120/13). Em seguida, foi feito o convite aos homens para a participação na pesquisa. O convite foi feito via telefone, momento no qual foi possível informar sobre os objetivos da pesquisa, verificar o interesse dos homens para a participação no estudo, assim como o melhor local para a realização das entrevistas.

As entrevistas foram orientadas por um roteiro semiestruturado que abordou os dados sociodemográficos dos participantes, bem como suas concepções acerca dos conceitos de saúde-doença-cuidado, o diagnóstico do câncer de próstata e as formas de lidar com a confirmação da doença e suas repercussões. Dentre o total de entrevistas realizadas, 7 delas ocorreram nas residências dos participantes (uma delas foi anulada, em virtude do entrevistado ter tido suas respostas respondidas por um familiar) e 2 delas foram feitas em uma clínica escola de Psicologia. Todas as entrevistas ocorreram com a presença de uma pesquisadora e o entrevistado.

Com cada um dos participantes houve um momento prévio para a explicação dos objetivos da pesquisa, com a leitura e assinatura do Termo de Consentimento Livre e Esclarecido, seguido pela realização da entrevista. As entrevistas tiveram duração média de 40 minutos, foram gravadas, transcritas na íntegra e lidas de forma exaustiva e curiosa ${ }^{21}$ para que os temas mais significativos pudessem emergir das falas dos entrevistados ${ }^{22}$, o que resultou na construção de três grandes temáticas, que descrevem e analisam as vivências dos participantes frente ao diagnóstico de câncer de próstata.

\section{RESULTADOS E DISCUSSÃO}

Neste espaço são apresentados os participantes do estudo, assim como as temáticas que emergiram das entrevistas, a saber: a identidade masculina diante do adoecimento por câncer de próstata; o diagnóstico, o tratamento e suas implicações.

A média de idade dos participantes foi de $69,3 \pm 8,5$ anos. Em relação ao trabalho, somente 2 homens referiram que estavam trabalhando (E1 e E8). Entre as atividades citadas encontra-se pedreiro (E1), gari (E2), vigilante (E3), mestre de obras (E4), lavrador (E5 e E8), motorista (E6) e, um aposentado (E7). O tempo de diagnóstico do câncer esteve no intervalo entre 3 meses e 20 anos. Do total dos participantes, somente um afirmou ter histórico familiar de câncer (E7).

\section{A identidade masculina diante do adoecimento por câncer de próstata}

A masculinidade está presente na formação da identidade do homem, ditando normas a serem seguidas ${ }^{10}$. Ser homem é um exercício de intensa negação, em que se negam, por exemplo, particularidades femininas na tentativa de se aproximar do que se acredita ser a imagem ideal de homem, construída culturalmente ao longo da história ${ }^{18}$. Nesse sentido, são internalizados comportamentos que reforcem a imagem masculina, que é associada à força, superioridade, coragem, conquista, determinação e virilidade $e^{6,10,17,23}$. Essa internalização da força, como característica de masculinidade, pode ser notada no discurso de um dos entrevistados apresentado na sequência.

“(...) Assim que é a natureza da gente, trabaiá, ser forte (...). Só nas fazenda foi uns quarenta anos, mais dez aqui na prefeitura (...)" (E2)

O trabalho também é um espaço que contribui para a construção da identidade masculina e garantia 
da autoridade do homem na família ${ }^{18}$. Além disso, é um espaço de socialização que ultrapassa a dimensão financeira e econômica, proporcionando sentimentos de autonomia, confiança, reconhecimento de esforços, dignidade ${ }^{6,24}$, além de poder ser um promotor de saúde psíquica ${ }^{25}$. Dessa forma, receber o diagnóstico de câncer de próstata e se ver diante da impossibilidade de trabalhar, fez com que os participantes se percebessem como seres improdutivos ou incapazes, implicando em uma crise de identidade, marcada por sentimentos de baixa autoestima e perda do significado da vida, como se pode observar nas falas apresentadas a seguir.

"A doença é uma coisa ruim que acontece pra gente né (...). Que tira a alegria da vida, o trabalho, a COmida." (E1)

"Uai, a doença me entendo assim que a pessoa que não pode e não dá pra trabalhar sempre (...). Não tem aquele ânimo que tinha de primeira, como diz tem vontade, mas não tem condição fazer, não dá conta do serviço." (E5)

“(...) doença é um trem que assim, um trem que você fica inválido, imprestável, não pode movimentar, mexer. Pra mim já acabou o viver daquela pessoa, então pode morrê logo e jogar dentro de um buraco." (E6)

"Mas é isso, o sentimento é que a gente é impotente mesmo, essa doença é, é meio forte." (E7)

Concordando com autores como Duarte et al. ${ }^{19}$, ao afirmarem que o diagnóstico de câncer de próstata pode despertar sentimentos de exclusão e o distanciamento de grupos sociais. Sobre isso, algumas falas dos entrevistados também evidenciaram o sofrimento sobre terem que ficar em casa em virtude da doença, como se pode acompanhar na sequência.

\footnotetext{
"Uai eu acho difícil que a pessoa que não tem assim paciência de ficar quieta e vai ficando, parece que vai dando aquela depressão de vontade de fazer as coisas né e não dá conta e não pode. É o que eu ia falando pra você, e meus filhos também proibiu a gente de sair assim com medo de cair na rua, machucar ou acontecer qualquer coisa." (E5)

"Não porque a gente é acostumada a trabalhar todo dia né, é bom exercitar o corpo, agora você ficar parado assim enjoa de deitar. Mas fazer o que, né, tem que esperar." (E3)
}

Dessa forma, a chegada do câncer pode favorecer a perda dos referenciais pelos quais os homens se reconhecem enquanto produtivos, provedores e protetores, podendo relacionar-se à subtração da masculinidade ${ }^{18,20,26,27}$, à tristeza e à sensação de invalidez.

\section{O diagnóstico}

Mesmo com os avanços tecnológicos e científicos, o câncer ainda é carregado de estigmas e preconceitos. Além de ser vivido de forma temida pode despertar algumas reações como medo, ansiedade e depressão ${ }^{14}$. Dessa maneira, o diagnóstico de câncer pode assumir um caráter trágico e despertar pensamentos que influenciam o estado emocional do indivíduo, como por exemplo, o de que o câncer é uma doença que causa uma morte rápida ${ }^{14}$, como é constatado nas falas dos entrevistados apresentadas na sequência.

\begin{abstract}
"Mas essa doença, eu sei que nunca cura, as veiz demora mais um pouco, outros morre mais rápido. Teve pessoa que já morreu ai durante um mês mais ou menos." (E1)

"Ah eu pensei assim que é uma doença assim muito apavorosa, né. O tal do falar em câncer, eu achava que era uma doença muito pavorosa, pensava assim isso dentro de poucos dias isso mata a gente." (E3)

"A gente fica na depressão, quer ficar só dentro de casa, só isolado, né, não quer nem conversar com as outras pessoas. (...) a gente fica machucado, tudo acaba pra gente." (E1)
\end{abstract}

A partir das falas apresentadas, pode-se observar a crença de que o câncer é uma doença grave, muitas vezes incurável e associada à morte ${ }^{6,13}$. Além disso, essas concepções podem estar associadas a dificuldade de se conversar sobre a enfermidade, ou mesmo em pronunciar a palavra câncer ${ }^{6}$.

Ainda em relação às representações da enfermidade, o termo doença pode despertar nas pessoas a ideia de sofrimento e impossibilidade de levar uma vida considerada como normal ${ }^{20,28}$, fato que também está presente nas falas de alguns entrevistados, enquanto que a saúde se contrapõe ao que eles consideram como doença, como se pode acompanhar a seguir.

"Cêdoeceucabô a pessoa, eu considero assim adoeceu não presta mais." (E6)

“(...) doença joga todo mundo, qualquer, qualquer pessoa pra trás, né." (E8)

"A saúde para mim acho que é a pessoa ficar livre da doença." (E1)

"Pra mim saúde é uma coisa muito importante. Uai, é uma coisa boa, né, é um previlégio que não é pra todo mundo, né (...)" (E4)

"Saúde é cê ter toda disposição, coragem, vontade de fazer e comer e viver, andar, passear, divirtir, tudo é saúde, né (risos), eu penso assim." (E6) 
Diante do sofrimento experimentado com a chegada da doença, os entrevistados buscaram como rede de suporte, o médico, a família e a religiosidade/espiritualidade, os quais os auxiliaram a conviver com o adoecimento, como se pode acompanhar a seguir.

"(...) tudo que o doutô passa pa gente, a gente tem que fazer, fazer toda força de seguir direitinho mesmo." (E2)

"Então, tudo que ele fala pra mim que tem que fazer, tem que fazer. Eu faço toda força de andar em cima da linha lá, pa vê se tudo acontece certo." (E3)

"Mas aí o médico falou tem, tem, vamo caça jeito de curar então, que tem cura, tem, então vamo cuidar." (E6)

No que diz respeito a influência que o médico pode ter no comportamento do paciente frente à doença, é possível verificar que eles contribuem de forma direta para que os pacientes superem a doença e o sofrimento, a partir da crença revelada por esses profissionais sobre a possibilidade de cura ${ }^{28}$. O apoio dos familiares também é considerado um fator que auxilia na aceitação e no enfrentamento da doença ${ }^{1,7}$. Sobre isso, E2 referiu-se à esposa como sua cuidadora.

"Ai eu tenho minha véia, né. Tem a véia que faz tudo aqui, né, é a minha véia que cuida, ela trabaia dezessete horas tem dia, por dia, né. Ela levanta de madrugada, a véia é que cuida de nóis, da gente." (E2)

Por último, a religiosidade/espiritualidade foi citada pelos participantes como forma de auxílio para o enfrentamento da doença, suscitando esperança e crença na cura, ou ainda para compreender a morte de uma forma diferente, como é possível visualizar na sequência.

"Eu fico com medo assim, porque eu nunca passei por isso, ai eu entrego na mão de Deus, né, porque Deus sabe o que que vai acontecer comigo. Posso ir e não voltar, mas vai dar tudo certo se Deus quiser." (E6)

"Entrega na mão de Deus, se Deus quiser que ocê fica mais tempo ele cura, livra de tudo e pronto. Deus faz a parte dele, o médico faz a parte dele, mas Deus que manda em tudo, né (...)" (E6)

"Eu sou espiritualista. Temos que deixar de ser esse corpo, porque o corpo é um instrumento, se você vai morrer, morre só o corpo." (E4)

A prática religiosa é compreendia como rede de apoio principalmente perante situações difíceis como o diagnóstico de um câncer, responsável por causar grande impacto na vida do indivíduo ${ }^{29}$, porque pode representar um possível fator de prevenção do desenvolvimento de doenças, além de uma provável redução no índice de mortalidade ${ }^{6}$.

\section{O tratamento e suas implicações}

Enfrentar um câncer acarreta muitos prejuízos, pois é uma doença que afeta o indivíduo fisicamente, psicologicamente, além de modificar o modo de relacionamento do indivíduo consigo mesmo e com os outros. O tratamento, muitas vezes, iniciado em um estadio mais avançado, promove sentimentos de angústia vinculados ao medo da morte ${ }^{1,30}$, como se pode acompanhar a seguir.

"Porque tem o maligno e o, aquele outro. Aí falei, o perigo é o medo de morrer (...). Eu fiquei com medo, porque minhas próstata ele não tirou ela tudo, né, fez só uma raspagem quando eu operei." (E8)

Nos relatos dos participantes deste estudo, no que se refere ao tratamento e suas implicações, foi notável também o destaque para as mudanças de hábitos, além do constante desgaste ocasionado pelas viagens para outros municípios visando a realização do tratamento, como é possível visualizar na sequência.

“(...) é, é cansa demais, incha muito os pé (...). (...) é porque nóis vai e volta no mesmo dia, ai chega de noite. Tem dia que vem mais cedo e o micro-ônibus é muito curtinho, os juêi meu fica machucando, então eu canso muito." (E2)

“(...) só uma viagem dessa aí já te cansa, tem que sair daqui uma hora da manhã né, até ocê ir vortar, cê passa sono o dia inteiro, vem, isso tudo já vai estragando sua saúde." (E8)

O deslocamento pode ser considerado um fator estressante para o tratamento ${ }^{31}$, além de acarretar desconforto para o paciente. Concordando com as falas dos entrevistados, que residem a uma distância de aproximadamente $320 \mathrm{~km}$ do local de realização do tratamento, o que foi apontado como gerador de muito cansaço.

Sobre as mudanças ocasionadas pelo tratamento, por exemplo, na fala de E1, foram notadas transformações significativas em seus hábitos cotidianos, associados com alimentação e repouso.

"Uai, a gente fica ruim, né, vai passando o tempo, vai ficando mais probrema. Antigamente eu comia, eu bebia, eu dormia, né. Agora quando tá atacado mesmo, hoje eu fico três, quatro noites sem dormir (...). Com a doença muitas coisas que a gente gostava de comer, já não pode comer mais." (E1)

Ainda em relação à mudança de hábitos decorrentes do tratamento, a redução na ingestão de bebidas alcoólicas também se apresentou como relevante para os 
entrevistados, alguns relataram a ingestão mínima ou nula do álcool.

"Bom, sempre os cuidados a gente toma assim antes de beber, às vezes, a gente exagera muito em bebida, eu gosto muito de tomar uma pinguinha, então eu manerei $(\ldots)^{\prime \prime}(\mathrm{E} 3)$

“(...) porque nóis não pode ter vida de álcool, não pode fumar, então carne tem que comer muito pouco." (E2)

Os relatos dos participantes sobre as repercussões do diagnóstico de câncer de próstata demonstram, portanto, que os cotidianos dos entrevistados sofreram significativas mudanças com a chegada da doença, promovendo reflexões sobre a identidade masculina, bem como o lidar com as limitações impostas pela doença e seu consequente tratamento, mas que foram amenizadas com uma rede de suporte representada pela família, pelos médicos e pela religiosidade/espiritualidade.

\section{CONSIDERAÇÕES FINAIS}

Os participantes deste estudo ao serem indagados sobre suas vivências perante o diagnóstico de câncer de próstata, relataram sentimentos de angústia e ansiedade, ao associarem a enfermidade à morte. Além disso, o adoecimento promoveu mudanças significativas na vida dos homens entrevistados, afetando suas identidades, que diante do sofrimento experimentado buscaram apoio na família, nos médicos e na religiosidade/espiritualidade como forma de apoio para o enfrentamento da problemática representada pelo câncer de próstata, o que demonstra a relevância de redes de suporte para o enfrentamento de problemas como o diagnóstico dessa enfermidade.

Apesar da limitação da pesquisa, que entrevistou apenas uma parcela da população que reside em um município do interior do estado de Goiás que recebeu o diagnóstico de câncer de próstata, o presente estudo possibilitou a compreensão de como os homens participantes vivenciam o diagnóstico do câncer de próstata. Dessa forma, pode oferecer subsídios para intervenções com este público, visando a minimização do sofrimento gerado pelo adoecimento.

Os dados mostram a importância de se desenvolver e investir em espaços de cuidado destinados a pacientes oncológicos e seus familiares, como grupos de reflexão, nos quais questões como as alterações na identidade masculina possam ser discutidas, assim como o cuidado com os cuidadores, atendendo a demanda de munícipios localizados distantes dos grandes centros urbanos, onde atualmente são realizados os tratamentos. Outro aspecto que merece ser desenvolvido é o fortalecimento de redes de informação sobre a prevenção do câncer de próstata.
Por fim, considera-se relevante um maior investimento na produção de conhecimento sobre o assunto, visto a escassez de estudos que abordem as especificidades do ser homem perante o câncer de próstata.

\section{REFERÊNCIAS}

1. Moscheta MDS, Santos MA. Grupos de apoio para homens com câncer de próstata: revisão integrativa da literatura. Cienc Saúde Coletiva. 2012;17(5):1225-33. http://dx.doi.org/10.1590/S141381232012000500016

2. Instituto Nacional do Câncer (BR). Tipos de câncer [Internet]. [acesso em 2016 abr. 22]. Disponível em: http://www2.inca.gov.br/ wps/wcm/connect/tiposdecancer/site/home/prostata+/definicao

3. Bertoldo SA, Pasquini VZ. Câncer de próstata: um desafio para a saúde do homem. Rev Enferm UNISA. 2010;11(2):138-42.

4. Instituto Nacional do Câncer (BR). Monitoramento das ações de controle do câncer de próstata [Internet]. [acesso em 2015 maio 23]. Disponível em: http://www1.inca.gov.br/inca/Arquivos/Informativo Deteccao_Precoce_2_agosto_2014.pdf

5. Paiva EP, Motta MCS, Griep RH. Conhecimentos, atitudes e práticas acerca da detecção do câncer de próstata. ACTA Paul Enferm. 2010;23(1):88-93. http://dx.doi.org/10.1590/S010321002010000100014

6. Modena CM, Martins AM, Gazzinelli AP, Schall VT. Câncer e masculinidades: sentidos atribuídos ao adoecimento e ao tratamento oncológico. Temas em Psicol. 2014;22(1):67-78. http:// dx.doi.org/10.9788/TP2014.1-06

7. Vieira CG, Araújo WS, Vargas DRM. O homem e o câncer de próstata : prováveis reações diante de um possível diagnóstico. Rev Cient ITPAC. 2012;5(1):1-9.

8. Pinto BK, Muniz RM, Schwartz E, Budó MLD, Heck RM, Lange C. Identidade do homem resiliente no contexto de adoecer por câncer de próstata: uma perspectiva cultural. Rev Bras Enferm. 2014;67(6):942-8. http://dx.doi.org/10.1590/00347167.2014670612

9. Pinheiro TF, Couto MT, Silva GSN. Questões de sexualidade masculina na atenção primária à saúde: gênero e medicalização. Interface Comun Saúde Educ. 2011;15(38):845-58.

10. Belinelo RGS, Almeida SM, Oliveira PP, Onofre PSDC, Viegas SMDF, Rodrigues $A B$. Exames de rastreamento para o câncer de próstata: vivência de homens. Rev Enferm. 2014;18(4):697-704.

11. Gomes R. Sexualidade masculina e saúde do homem: proposta para uma discussão. Cienc Saúde Coletiva. 2003;8(3):825-9. http:// dx.doi.org/10.1590/S1413-81232003000300017

12. Vieira LJES, Santos ZMSA, Landim FLP, Neta CAS. Prevenção do câncer de próstata na ótica do usuário portador de hipertensão e diabetes. Cienc Saúde Coletiva. 2008;13(1):145-52. http://dx.doi. org/10.1590/S1413-81232008000100019

13. Aquino VV, Zago MMF. The meaning of religious beliefs for a group of cancer patients during rehabilitation. Rev Lat Am Enfermagem. 2007;15(1):42-7. http://dx.doi.org/10.1590/S010411692007000100007

14. Silva SDS, Aquino TAA, Santos RM. O paciente com câncer: cognições e emoções a partir do diagnóstico. Rev Bras Ter Cogn. 2008;4(2):73-88. 
15. Veit MT, Carvalho VA. Psico-Oncologia: um novo olhar para o câncer. Mundo Saúde. 2010;34(4):526-30.

16. Aratangy LR. O anel que tu me deste: o casamento no divã. Artemeios. São Paulo: Sobral S; 2007.

17. Tagliamento G, Toneli MJF. (Não) trabalho e masculinidades produzidas em contextos familiares de camadas médias. Psicol Soc. 2010;22(2):345-54. http://dx.doi.org/10.1590/S0102-71822 010000200015

18. Chapple A, Ziebland S. Prostate cancer : embodied experience and perceptions of masculinity. Qual Health Res. 2012;22(9):1184-94.

19. Duarte LFD, Leal OF. Doença, sofrimento, perturbação: perspectivas etnográficas. Rio de Janeiro: FIOCRUZ; 1998.

20. Martins AM, Gazzinelli AP, Almeida SSL, Modena CM. Concepções de psicólogos sobre o adoecimento de homens com câncer. Psicol Teor Prat. 2012;14(2):74-87.

21. Mcnamee S, Hosking DM. Research and social change: a relational constructionist approach. New York: Routledge; 2012.

22. Spink MJP. Desvendando as teorias implícitas: uma metodologia de análise das representações sociais. In: Guareschi P, Jovchelovitch S, organizadores. Textos em representações sociais. Petrópolis: Vozes; 2000. p. 117-45.

23. Souza LMelo, Silva MP, Pinheiro IDS. Um toque na masculinidade: a prevenção do câncer de próstata em gaúchos tradicionalistas.
Rev Gaúcha Enferm. 2011;32(1):151-8. http://dx.doi.org/10.1590/ S1983-14472011000100020

24. Sarti CA. A família como espelho: um estudo sobre a moral dos pobres. São Paulo. Cortez; 2005.

25. Faiman CJS. Psicoterapia em ambulatório de saúde do trabalhador: possibilidades e desafios [tese]. São Paulo: USP; 2012.

26. Almeida SSL. Adoecer por câncer [dissertação]: sentidos do cuidado, enfrentamento e bem-estar de homens e seus cuidadores. Belo Horizonte: FIOCRUZ; 2013.

27. Viorst J. Perdas necessárias.São Paulo: Melhoramentos; 1988.

28. Oliveira AP, Gomes AMTA. A estrutura representacional do câncer para os seus portadores: desvelando seus sentidos e dimensões. Rev Enferm UERJ. 2008;16(4):525-3.

29. Guimarães HP, Avezum A. O impacto da espiritualidade na saúde física. Rev Psiquiatr Clin. 2007;34(1):88-94. http://dx.doi. org/10.1590/S0101-60832007000700012

30. Elmescany ENM. A arte na promoção da resiliência: um caminho de intervenção terapêutica ocupacional na atenção oncológica. Rev NUFEN. 2010;1(2):21-41.

31. Gontijo IBR, Ferreira CB. Sentimentos de mulheres jovens frente ao diagnóstico de câncer de mama feminino Feelings of young women facing diagnosis of female breast cancer. Ciênc Saúde (Porto Alegre). 2014;7(1):2-10. 